\title{
SIMULATIONS OF BIO-MICRO HIGH POWER DENSITY POWER GENERATION SYSTEM FOR ZERO ENERGY BUILDING
}

\author{
Hariyotejo Pujowidodo ${ }^{1 *}$, Ahmad Indra Siswantara ${ }^{2}$, Budiarso $^{3}$ \\ ${ }^{1}$ Centre for Thermodynamics, Engine and Propulsion, BPP Teknologi, Serpong 15314, Indonesia \\ ${ }^{2,3}$ Department of Mechanical Engineering, Faculty of Engineering, Universitas Indonesia, Depok \\ 16424, Indonesia
}

(Received: July 2018 / Revised: August 2018 / Accepted: January 2019)

\begin{abstract}
The study of bio-micro high power density power generation system simulations for Zero Energy Building (ZEB) has been done, by analyzing the improvement momentum parameters for rotating impulse power turbines refers to the potential local bio-renewable energy sources. The main improvement parameters which are velocity and mass flow would be analyzed in dynamic simulations of the thermal power generation system to give the estimated fuel rate requirement for appropriate heat enthalpy and predicted output power. Input parameters of simulation such as pressure, temperature, mass flow determined as design points of the thermodynamic cycle. Using the fuel rate range $0.1-1 \mathrm{~kg} / \mathrm{s}, \mathrm{LHV} 12000 \mathrm{~kJ} / \mathrm{kg}$, and steam temperature from 120-165 oC, could predict the output power more than $300 \mathrm{~kW}$. For power turbine demand range from $100-300 \mathrm{~kW}$, it requires fuel rate $0.5-1 \mathrm{~kg} / \mathrm{s}$ ( $\mathrm{LHV}=12000 \mathrm{~kJ} / \mathrm{kg}$ ) and saturated steam pressure $360-700 \mathrm{kPa}$. This simulation model could give the conceptual design of thermal power generation for ZEB.
\end{abstract}

Keywords: Bio-renewable energy sources; Dynamic simulations; Enthalpy; Isentropic; Momentum parameters

\section{INTRODUCTION}

Basically, in power generation system there is an energy conversion process which heat energy transferred into electrical energy through rotating equipment. Heat energy contained in substance enthalpy comes from the transformation of chemical energy in the combustion process. Then this potential energy will change into kinetic energy to rotate the generator. The output power of this conversion depends on the heat source and the magnitude of momentum strikes to the turbine's blade runner. Momentum transfer occurs in the nozzle section in the turbine unit and has the function to increase the velocity.

The study of the nozzle as the essential component in the turbine unit has many done by the researchers to more understand and help in design optimization. The main design parameters such as temperature, pressure, flow rate, and geometry as well are many analyzed, refers to the constraint of dimension and operating condition. The potential head conversion had been reviewed as one of the crucial parameters for high-efficiency impulse turbine (Adhikari \& Wood, 2018) The maximum effective velocity had been extracted from enthalpy drop in combustion much affected by the proper geometrical design (Belega \& Nguyen, 2015).

\footnotetext{
*Corresponding author's email: hariyotejo.pujowidodo@bppt.go.id Tel. +62-81-210406063
} 
The effect of geometry also had been studied by computational model to analyze the pressure, velocity, and density in the rocket (Narayana \& Reddy, 2016). The momentum flux had been modeled computationally to analyze the main parameters of geometry and operating condition (Pandey \& Singh, 2010) deeply. Investigation the geometry shape of the cross-sectional area in convergent-divergent nozzle had concluded that these factors strongly influenced the flow properties such as temperature, pressure, velocity, and expansion condition (Satyanarayana et al., 2013). To obtain the optimum supersonic flow in the converging-diverging nozzle also had been reported by analyzing the back pressure and area ratio (Shariatzadeh et al., 2015). The more intensive analysis of the particular geometry and inlet condition in the nozzle of jet ejector application had been done to design the optimum output velocity (Singhal et al., 2013).

This paper will describe the study of a simulation model for bio-micro thermal power generator utilizing the renewable energy. As the constraint of this simulation is fuel rate and the saturated steam temperature while the assumptions adopted are an isentropic process for expansion and compression on the turbine and pump, the efficiency of combustion and boiler efficiency. Based on this given parameters, the simulation will calculate the magnitude of predicted output turbine power, the dimension of sectional cross-area of nozzle outlet. As well, using the simulation would give the estimated performance system with the input of actual measuring parameters such as pressure, the temperature at the inlet-outlet of each sub-component in the system.

\section{LITERATURE STUDY}

The bio-micro power generation system utilized saturated steam as the momentum source to rotate the turbine power. As the fuel source using the solid biomass, burning in the boiler to produce the combustion heat and evaporates water inside. The steam flow passes through the nozzle section and transfers potential energy to kinetic energy in the impulse turbine. And then the output expansion fluid returned by pumping the condensate fluid to the boiler.

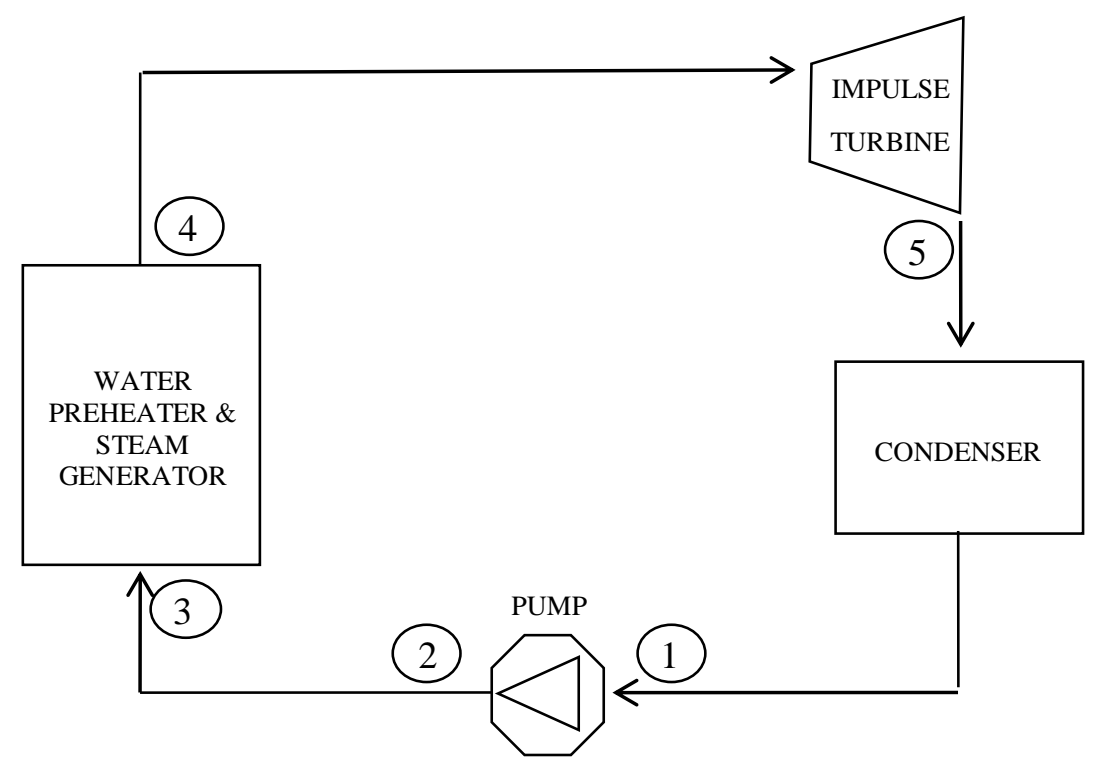

Figure 1 The Micro Power Generation System - Diagram

Thermodynamics cycle of this power cycle is the Rankine cycle where the steam is operated in a saturated condition and expanded into the vapor liquid. The condensed fluid will be subcooled until the fluid enters the pump about sub-cooled temperature $50 \mathrm{oC}$. The condenser operates at atmospheric condition. 


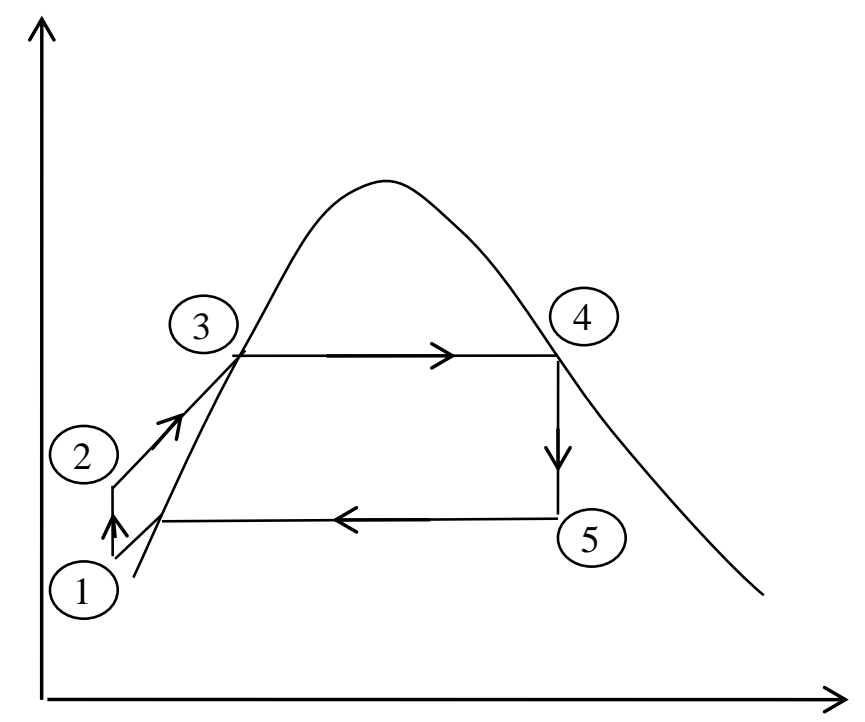

Figure 2 The Micro Power Generation System - Thermodynamics Cycle

Each at state points in the power cycle describes the process chain from isentropic compression (1-2), heating and evaporating in the steam generator (2-3-4), isentropic adiabatic expansion in impulse turbine (4-5), condensing and subcooling in the condenser (5-1). Thus, this process is a closed system where energies come in and come out. Provide sufficient detail of the literature review to allow the work to be.

\section{METHODS}

The simulation models built from the defining the equation of energy and mass balance as written in the following thinking-flow.

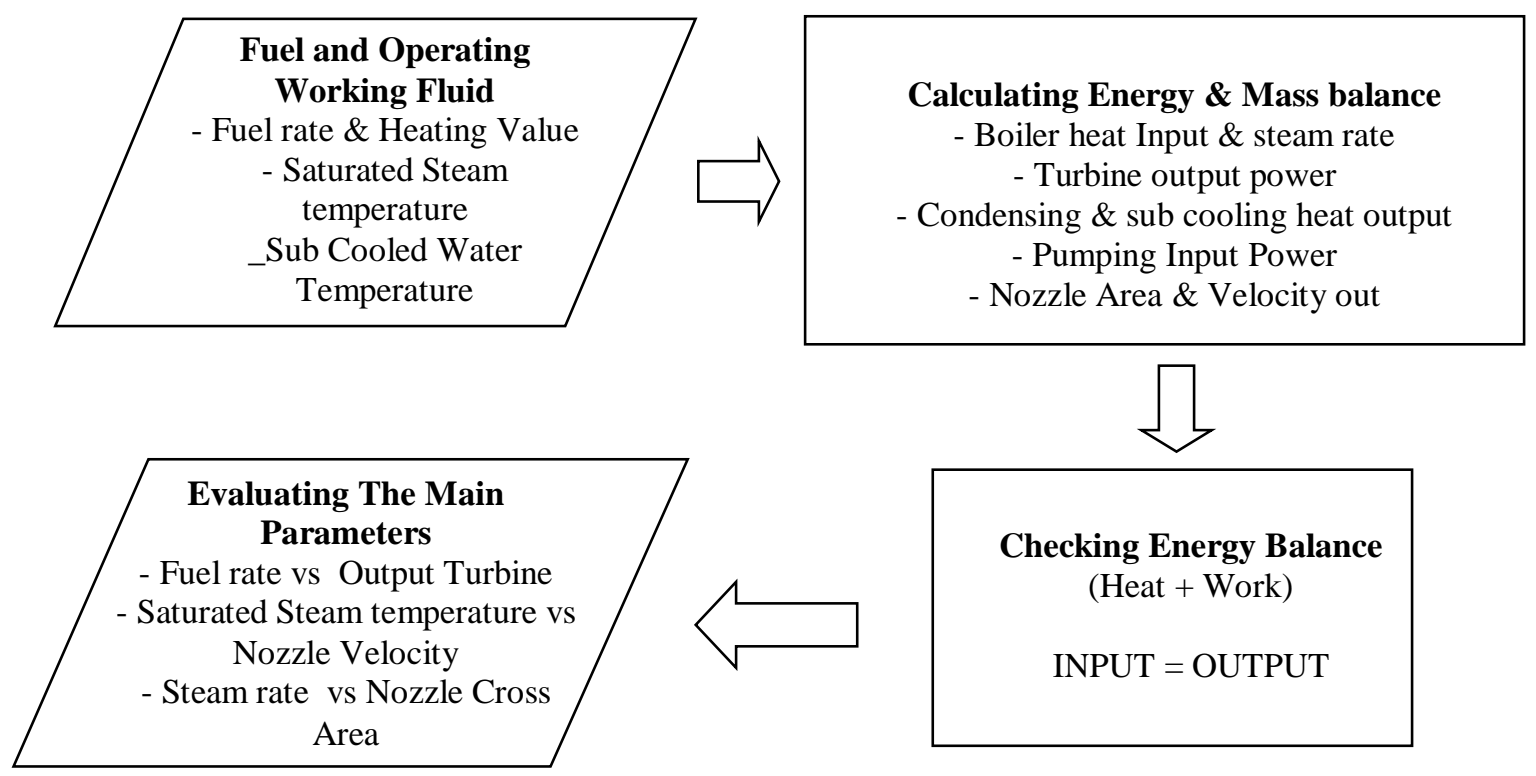

Figure 3 The Micro Power Generation System - Thinking.

For calculating the energy and mass balance, there could be defined the equation based on the enthalpy and mass flow for every state points. In the steam generator the steam heat input determined from the fuel energy and combustion and boiler efficiency (assumed $\eta c=0.7$ and 
$\eta$ th $=0.4)$. The steam mass flow calculated with dividing heat input to steam generator by delta enthalpy of output and input.

$$
\begin{gathered}
Q_{b}=\eta_{c} \cdot \eta_{t h} \cdot\left(m_{b b} \cdot L H V\right) \\
m_{s t}=\frac{Q_{b}}{\left(h_{4}-h_{2}\right)}
\end{gathered}
$$

Turbine output power with the same manner, predicted using the equation of steam mass flow and enthalpy drop coming in and out multiplies with the isentropic adiabatic efficiency (taken $\eta_{\mathrm{t}}$ $=0.7$ ), as the following equation.

$$
W_{t, a}=\eta_{t} \cdot m_{s t} \cdot\left(h_{4}-h_{5}\right)
$$

Before heating and evaporating in the steam generator, working fluid comes out from the turbine would be condensed and subcooled where the enthalpy drop calculated by the difference of enthalpy out turbine and enthalpy of subcooled liquid at a certain temperature before enters the pump. This can be determined using the equation below.

$$
Q_{c}=m_{s t} \cdot\left[\left(h_{5}-h_{1}\right)\right]
$$

The work supplied for the pumping process, calculated using the isentropic adiabatic compression (assumed $\eta t=0.7$ ) and pressure difference from output and input, and density of water as well.

$$
W_{p, a}=\frac{m_{s t} \cdot\left(p_{2}-p_{1}\right)}{\eta_{p} \cdot \rho_{w}}
$$

The influence of momentum parameters done by analysis the magnitude of velocity flowed out from the nozzle and based on the calculated steam mass flow would be used to obtain the area of cross-sectional. The following equations for analyzing the current and nozzle area are given in the following Critical Pressure Ratio (CPR) correlation to get pressure at the throat. The value of specific heat ratio $\mathrm{k}$ for steam is taken 1.3 .

$$
C P R=\left[\frac{2}{(k+1)}\right]^{\left(\frac{k}{k+1}\right)}
$$

For throat section of nozzle : 


$$
\begin{gathered}
P_{t, n}=C P R \cdot P_{4} \\
V_{t, n}=44.72 \cdot \sqrt{\left(h_{4}-h_{2 n}\right)} \\
A_{2, n}=m_{s t} \cdot \rho_{2, n} / V_{t, n}
\end{gathered}
$$

For exit section of nozzle :

$$
\begin{gathered}
V_{e, n}=44.72 \cdot \sqrt{\left(h_{2, n}-h_{5}\right)} \\
A_{3, n}=m_{s t} \cdot \rho_{3, n} / V_{e, n}
\end{gathered}
$$

The properties of enthalpy passes through the throat section (subscript-t) evaluated at throat pressure state, and the same way for determining the density of fluid at exit location.

\section{RESULTS AND DISCUSSION}

\subsection{Constraints value, Variables assumption, and Verification}

For calculation, refers to the isentropic process of compression and expansion, also the efficiency of a steam generator that is the multiplying from combustion and heat transfer efficiency, and the operating condition taken for simulation. Thus these parameters could be shown in the table below.

Table 1 Constraint Value and Calculation Input

\begin{tabular}{ccc}
\hline Parameters & Values & Units \\
\hline LHV & 12000 & $\mathrm{~kJ} / \mathrm{kg}$ \\
$\eta_{c}$ & 0.7 & - \\
$\eta_{t h}$ & 0.4 & - \\
$\eta_{t}$ & 0.7 & - \\
$\eta_{p}$ & 0.7 & 5 \\
Fuel rate $m_{b b}$ & $0.1-1$ & $\mathrm{~kg} / \mathrm{s}$ \\
Saturated Steam Temperature $T_{4}$ & $120-165$ & ${ }^{\circ} \mathrm{C}$ \\
Atmospheric Condensing $P_{1}$ & 100 & $\mathrm{kPa}$ \\
Sub cooled Temperature $T_{1}$ & 50 & ${ }^{\circ} \mathrm{C}$ \\
\hline
\end{tabular}

Verification of the results is conducted by analyzing the energy balance between the addition of steam generator heat and pumping work, compared to the addition turbine output work and heat out from condensing and subcooling in the condenser. 
Table 2 Verification of Energy Balance in the Power Generation System (Solve by EES®)

\begin{tabular}{|c|c|c|c|c|c|c|c|c|c|c|c|c|c|c|c|}
\hline $\mathrm{E}_{\mathrm{ES}_{\mathrm{S}} \text { Parame }}$ & Table & & & & & & & & & & & & & & $\square$ 回 \\
\hline Table 1 & ble 1 [cop & & & & & & & & & & & & & & \\
\hline${ }_{1.10}^{D}$ & $\begin{array}{l}\dot{m}_{\mathrm{bb}} \\
{[\mathrm{kg} / \mathrm{s}]}\end{array}$ & $\begin{array}{l}\mathrm{LHV}_{\mathrm{bb}} \\
{[\mathrm{kJ} / \mathrm{kg}]}\end{array}$ & ${ }^{3} \underset{\eta_{\text {comb }}}{\mathbf{V}}$ & ${ }_{[\mathrm{k} J / s]}^{\dot{Q}_{b}}$ & $\eta_{\text {th }}$ & $\begin{array}{c}\dot{Q}_{s t} \\
{[k \mathrm{k} / \mathrm{s}]}\end{array}$ & $\begin{array}{l}\mathrm{T}_{4}{ }^{5} \\
{[\mathrm{C}]}\end{array}$ & etat & $\begin{array}{l}\mathrm{Wt}_{\mathrm{a}} \\
{[\mathrm{kW}]}\end{array}$ & $\begin{array}{l}{ }^{T_{1}} \\
{[\mathrm{C}]}\end{array}$ & $\begin{array}{c}\dot{Q}_{c} \\
{[\mathrm{~kJ} / \mathrm{s}]}\end{array}$ & $\begin{array}{l}\dot{Q}_{\mathrm{sc}} \\
{[\mathrm{kJ} / \mathrm{s}]}\end{array}$ & etap $_{\mathrm{s}}$ & $\begin{array}{l}\mathrm{Wpa}_{\mathrm{a}} \\
{[\mathrm{kW}]}\end{array}$ & $\begin{array}{c}\Delta \mathrm{E} \\
{[\mathrm{kW}]}\end{array}$ \\
\hline Run 1 & 0.1 & 12000 & 0.7 & 840 & 0.4 & 336 & 120 & 0.7 & 10.97 & 50 & 292.3 & 28.01 & 0.7 & 0.01916 & $6.942 \mathrm{E}-07$ \\
\hline Run 2 & 0.2 & 12000 & 0.7 & 1680 & 0.4 & 672 & 125 & 0.7 & 26.88 & 50 & 577.8 & 55.85 & 0.7 & 0.05123 & 0.000002569 \\
\hline Run 3 & 0.3 & 12000 & 0.7 & 2520 & 0.4 & 1008 & 130 & 0.7 & 47.47 & 50 & 856.7 & 83.55 & 0.7 & 0.09869 & 0.000006701 \\
\hline Run 4 & 0.4 & 12000 & 0.7 & 3360 & 0.4 & 1344 & 135 & 0.7 & 72.52 & 50 & 1129 & 111.1 & 0.7 & 0.1644 & 0.00001481 \\
\hline Run 5 & 0.5 & 12000 & 0.7 & 4200 & 0.4 & 1680 & 140 & 0.7 & 101.8 & 50 & 1396 & 138.5 & 0.7 & 0.2514 & 0.00002953 \\
\hline Run 6 & 0.6 & 12000 & 0.7 & 5040 & 0.4 & 2016 & 145 & 0.7 & 135.1 & 50 & 1657 & 165.8 & 0.7 & 0.3632 & 0.00001721 \\
\hline Run 7 & 0.7 & 12000 & 0.7 & 5880 & 0.4 & 2352 & 150 & 0.7 & 172.2 & 50 & 1913 & 193 & 0.7 & 0.5037 & 0.0000284 \\
\hline Run 8 & 0.8 & 12000 & 0.7 & 6720 & 0.4 & 2688 & 155 & 0.7 & 213 & 50 & 2164 & 220 & 0.7 & 0.6772 & 0.00004497 \\
\hline Run 9 & 0.9 & 12000 & 0.7 & 7560 & 0.4 & 3024 & 160 & 0.7 & 257.3 & 50 & 2410 & 247 & 0.7 & 0.8883 & 0.00006886 \\
\hline Run 10 & 1 & 12000 & 0.7 & 8400 & 0.4 & 3360 & 165 & 0.7 & 304.8 & 50 & 2651 & 273.9 & 0.7 & 1.142 & 0.0001026 \\
\hline
\end{tabular}

The simulation model could give the good results with the residual calculation under 1.1e-4.

\subsection{Momentum Parameters Analysis}

The influence of velocity and mass flow as the analysis parameters, obtained from the input calculation data as given in Table 1 after simulation model has been verified, Nozzle as the essential component in turbine power to deliver the optimum momentum, depends strongly to the operating parameters and dimension of geometry. The change of flow properties such as pressure, density, and velocity influenced by the turbine output power, the higher fuel rate will change the steam rate linearly. This will cause the flow properties to change proportionally. The cross-sectional area at nozzle has the inverse proportionality to the steam rate.

Briefly, the velocity has linear proportionality to the steam rate and the inverse proportionality to cross-sectional area at throat section of the nozzle.

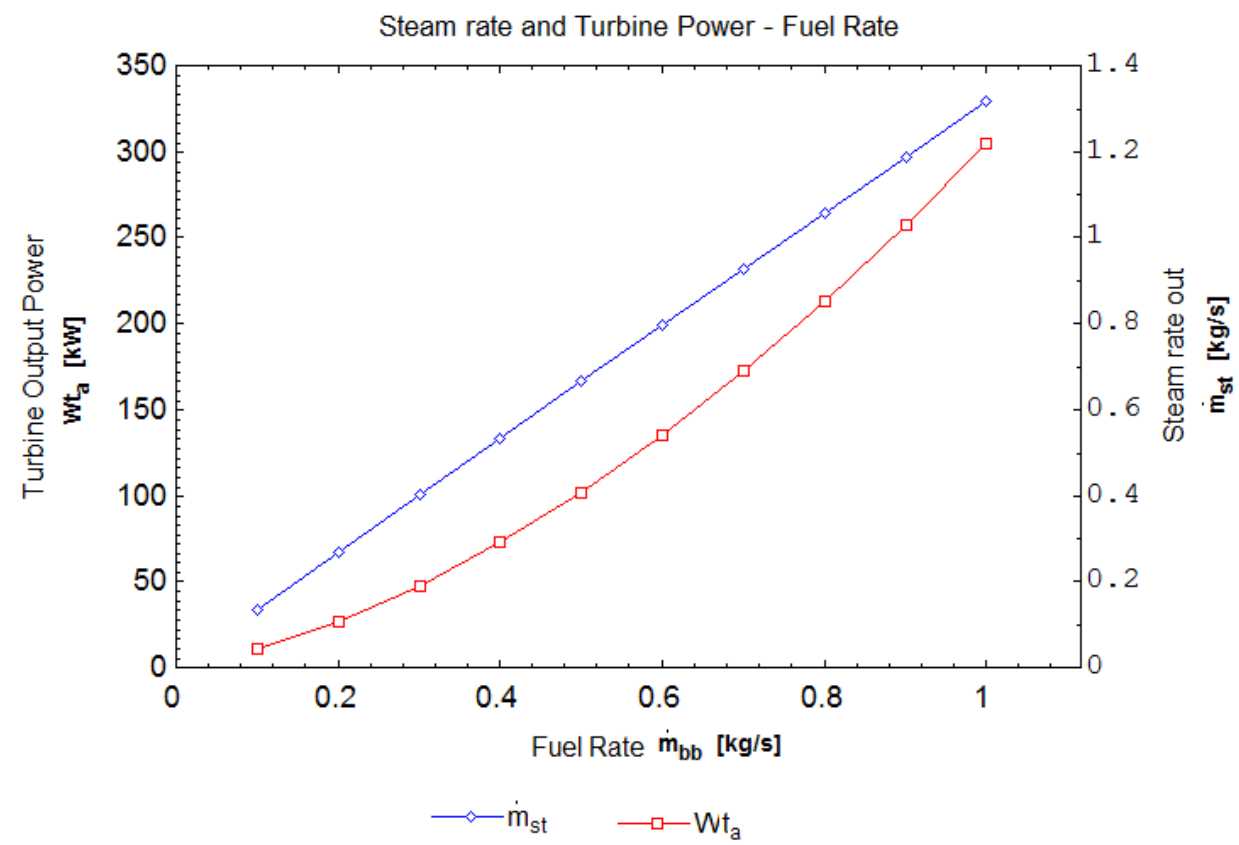

Figure 4 The Influence Fuel rate to Turbine Power and Steam rate (solved by EES®) 


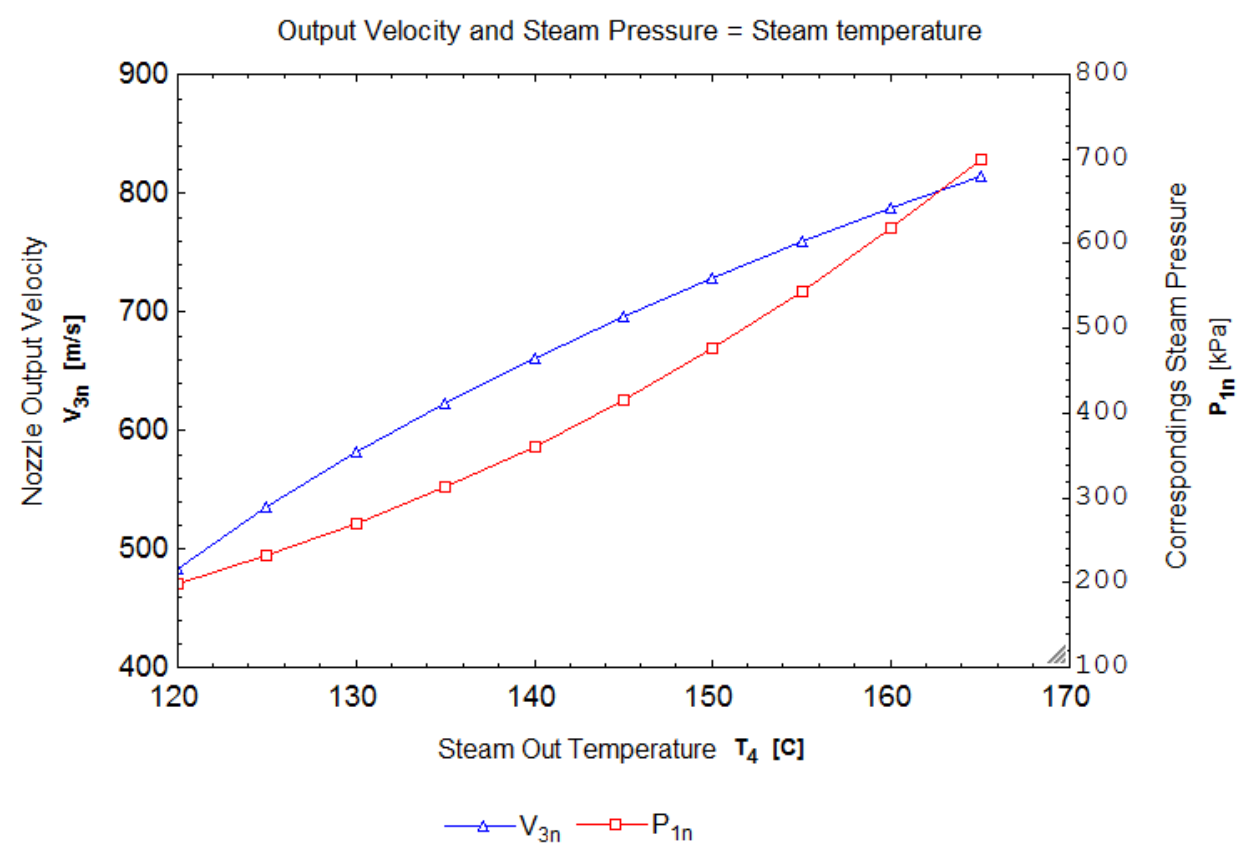

Figure 5 The Influence Steam rate to Output Velocity and Corresponding Steam Pressure (solved by EES®)

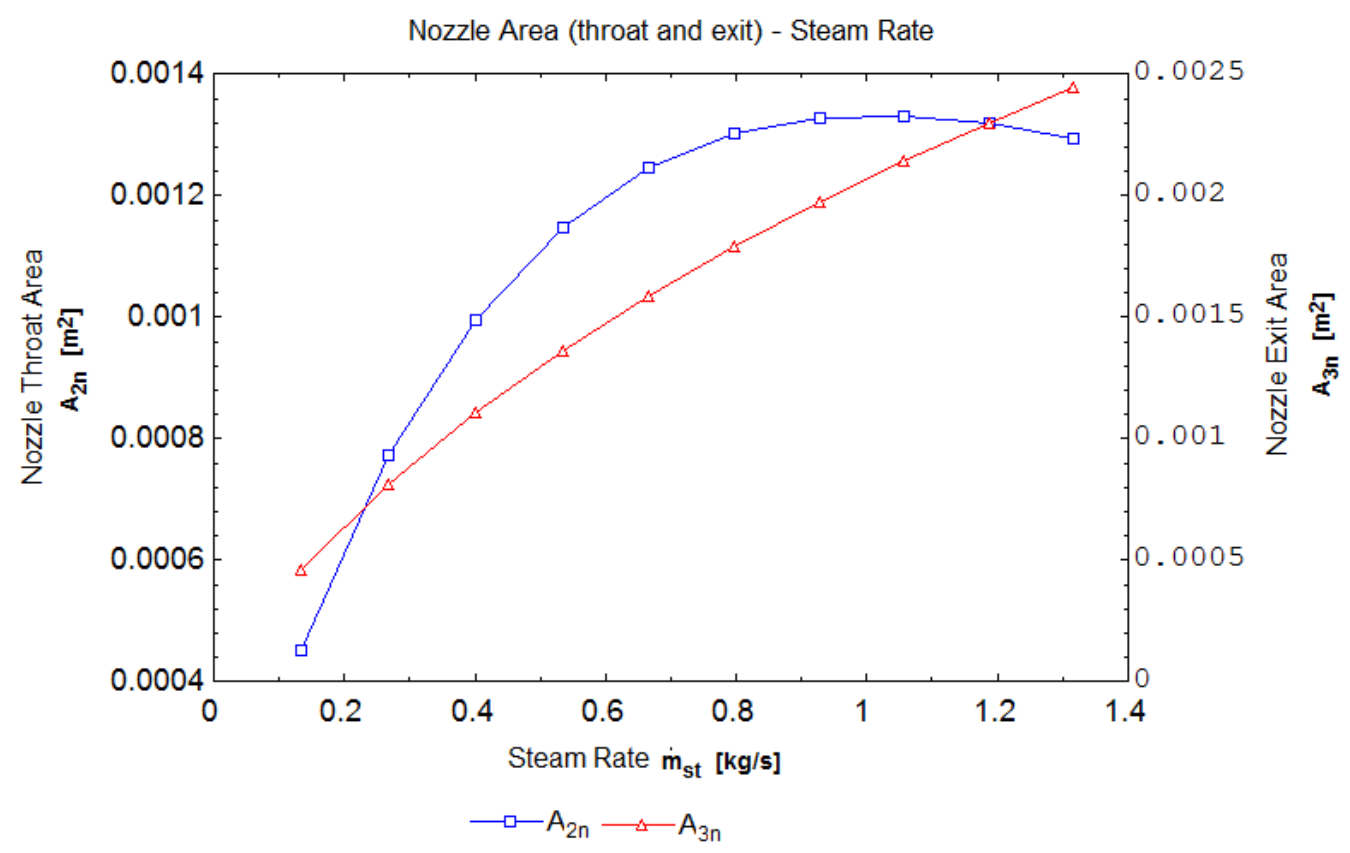

Figure 6 The Influence Steam rate to Nozzle Throat and Exit Areas (solved by EES®).

Refer to figure- 4 it could be obtained that the design of power turbine about $300(\mathrm{~kW})$, there is a demand of $1.3 \mathrm{~kg} / \mathrm{s}$ from saturated steam $700 \mathrm{kPa}$, from fuel rate $1 \mathrm{~kg} / \mathrm{s}$ ( $\mathrm{LHV}=12000$ $(\mathrm{kJ} / \mathrm{kg}))$. With this thermal enthalpy, could be gotten the supersonic velocity $813.5(\mathrm{~m} / \mathrm{s})$ from the converging-diverging nozzle with the dimension of areas are $12.92(\mathrm{~cm} 2)$ at throat and $24.46(\mathrm{~cm} 2)$ at the exit.

For estimation power turbine about $100 \mathrm{~kW}$, with fuel rate $0.5(\mathrm{~kg} / \mathrm{s})(\mathrm{LHV}=12000(\mathrm{~kJ} / \mathrm{kg}))$ it could given the steam rate about $0.7(\mathrm{~kg} / \mathrm{s})$ from saturated pressure $360(\mathrm{kPa})$. This steam 
enthalpy has the supersonic velocity with magnitude $661(\mathrm{~m} / \mathrm{s})$ from the dimension at throat and exit areas subsequently $15.85(\mathrm{~cm} 2)$ and $44.93(\mathrm{~cm} 2)$.

\section{CONCLUSION}

The simulation study of Bio-Micro Power Generation System has been completed, using the fuel rate range $0.1-1 \mathrm{~kg} / \mathrm{s}$ could predict the output power more than $300 \mathrm{~kW}$. This performance strongly affected by the isentropic process condition and the appropriate nozzle as the component to convert heat enthalpy into kinetic energy. The velocity much influenced by the pressure parameter while the mass flow depends highly on the nozzle cross-sectional area. For power turbine demand range from $100-300(\mathrm{~kW})$, it requires fuel rate $0.5-1(\mathrm{~kg} / \mathrm{s})$ $(\mathrm{LHV}=12000(\mathrm{~kJ} / \mathrm{kg}))$ and saturated steam pressure 360-700 $(\mathrm{kPa})$.

\section{ACKNOWLEDGEMENT}

The authors would like to thanks, DRPM Universitas Indonesia for funding this research through "Hibah Publikasi Internasional Terindeks untuk Tugas Akhir Mahasiswa UI 2018" with contract number 2367/UN2.R31/HKP.05.00/2018, and to PT. CCIT Group Indonesia for EES software license.

\section{REFERENCES}

Adhikari, R., Wood, D., 2018. The Design of High Efficiency Crossflow Hydro Turbines: A Review and Extension. Energies, 11(2), 267.

Belega, B.A., Nguyen, T.D., 2015. Analysis of flow in convergent-divergent rocket engine nozzle using computational fluid dynamics. In Proceedings of International Conference of Scientific Paper AFASES. Brasov, Romania.

Narayana, K.P.S.S., Sadhashiva, K.R., 2016. Simulation of Convergent Divergent Rocket Nozzle using CFD Analysis. IOSR Journal of Mechanical and Civil Engineering (IOSRJMCE), 2278-1684.

Pandey, K.M., Singh, A.P., 2010. CFD analysis of conical nozzle for mach 3 at various angles of divergence with fluent software. International Journal of Chemical Engineering and Applications, 1(2), 179.

Satyanarayana, G., Varun, C., Naidu, S.S., 2013. CFD analysis of convergent-divergent nozzle. Acta Technica Corviniensis-Bulletin of Engineering, 6(3), 139.

Shariatzadeh, O.J., Abrishamkar, A., Jafari, A.J., 2015. Computational Modeling of a Typical Supersonic Converging-Diverging Nozzle and Validation by Real Measured Data. J. Clean Energy Technol, 3(3), 220-225.

Singhal, A., k Chitkara, T., Ameenuddin, M., 2016. Design, CFD Analysis and Performance Evaluation of the Steam Jet Ejector. 